\title{
Are we intentionally destroying our habitat?
}

\author{
Tam-Tri Le \\ Centre for Interdisciplinary Social Research \\ Phenikaa University, Hanoi, Vietnam
}

30 November 2021

Destroying our own species' habitat can be considered suicidal behavior. Despite this simple realization - which is supported by the mounting evidence of man-made environmental degradation and corresponding suffering, we are still continuing to further decrease the quality of our living conditions. Is this irrational? Nonetheless, suicidal ideation is also formed by rational thinking - but such rationale is highly subjective and usually with insufficient or low-quality information input [1,2].

Why do humans carry out environmentally destructive behaviors if we know they are against our species' collective goals of surviving and thriving? According to the Theory of Planned Behavior, actions are determined by intentions (planning), whether with awareness or as automatic habitual sequences [3]. If so, we have to ask a seemingly ridiculous question given the seemingly ridiculous situation we are in: what is humanity planning to accomplish by destroying nature? There must be some kinds of fundamental problems within the reasoning process leading to humans' environmentally destructive behaviors. Even our current state of climate science is contributing to an eco-deficit culture due to Western monopoly issues [4].

Which values are prioritized when people think before carrying out destructive behaviors? What is being put on the cost-benefit scale? This depends heavily on the core cultural values. Thus, it is crucial to find a way to incorporate pro-environmental core cultural values into the collective human mindset [5].

\section{References}

1. Nguyen, M.-H., Le, T.-T., Nguyen, H.-K. T., Ho, M.-T., Nguyen, H. T. T., \& Vuong, Q.-H. (2021). Alice in Suicideland: Exploring the Suicidal Ideation Mechanism through the Sense of Connectedness and HelpSeeking Behaviors. International Journal of Environmental Research and Public Health, 18(7), 3681. https://doi.org/10.3390/ijerph18073681

2. Vuong, Q.-H., Nguyen, M.-H., \& Le, T.-T. (2021). A Mindsponge-Based Investigation into the PsychoReligious Mechanism Behind Suicide Attacks. Sciendo. https://doi.org/10.2478/9788366675599

3. Ajzen, I. (1985). From Intentions to Actions: A Theory of Planned Behavior. In J. Kuhl \& J. Beckmann (Eds.), Action Control (pp. 11-39). Springer Berlin Heidelberg. https://doi.org/10.1007/978-3-642-69746-3 2

4. Vuong, Q.-H. (2021). Western monopoly of climate science is creating an eco-deficit culture. Economy, Land and Climate Insight. Retrieved from: https://elc-insight.org/western-monopoly-of-climate-science-is-creatingan-eco-deficit-culture/

5. Vuong, Q.-H. (2021). The semiconducting principle of monetary and environmental values exchange. Economics and Business Letters, 10(3), 284-290. https://doi.org/10.17811/ebl.10.3.2021.284-290 